\title{
Prevalence of self-reported reproductive tract infections/sexually transmitted infections symptoms and treatment seeking behavior among the married tribal women in Udaipur, Rajasthan
}

\author{
Anjana Verma ${ }^{1 *}$, Ashish Patyal ${ }^{2}$, Medha Mathur ${ }^{1}$, Navgeet Mathur ${ }^{3}$, Jitendra Hirani ${ }^{1}$
}

\author{
${ }^{1}$ Department of Community Medicine, ${ }^{3}$ Department of General Medicine, Geetanjali Medical College, Udaipur, \\ Rajasthan, India \\ ${ }^{2}$ Department of Neuroanaesthesia, Walton centre, Liverpool, United Kingdom
}

Received: 27 July 2021

Accepted: 01 September 2021

\author{
*Correspondence: \\ Dr. Anjana Verma, \\ E-mail: anjanaverma504@gmail.com
}

Copyright: (C) the author(s), publisher and licensee Medip Academy. This is an open-access article distributed under the terms of the Creative Commons Attribution Non-Commercial License, which permits unrestricted non-commercial use, distribution, and reproduction in any medium, provided the original work is properly cited.

\begin{abstract}
Background: Indian tribes are culturally distinct communities, with unique traditions and practices. Lack of awareness and "culture of silence" about reproductive health issues among women in rural areas contributes to high burden of reproductive tract infections/sexually tract infections. Rural tribal women also suffer from ignorance, poverty and lack of access to quality health care, which makes them more vulnerable to RTIs/STIs.

Methods: It was a community based cross sectional study conducted among 200 tribal women living in rural Udaipur, Rajasthan. The study was conducted from May 2019 to November 2019. A predesigned, pretested and structured questionnaire was used to take the interview of eligible women. Questionnaire included questions about sociodemographic profile, questions to assess the knowledge regarding RTIs and history of occurrence of any RTI symptom in the past six months and; questions to assess the treatment seeking behaviour for RTI symptoms.

Results: Most of the participants were 26-35 years old.About 37\% gave the history of experiencing RTI symptoms, vaginal discharge being the most common (46\%) symptom. Regarding the treatment, most (34\%) of the females took treatment from government hospital, followed by $26 \%$ of women who bought the medicines direct from pharmacy (over the counter), about $16 \%$ consulted a private practitioner. Prevalence was found to be significantly higher in less educated, belonging to lower socioeconomic status and among non-users of contraceptive methods.

Conclusions: Health education and active participation of stakeholders in the reproductive health programs is essential to strengthen the ongoing schemes about improving reproductive health of tribal women.
\end{abstract}

Keywords: Reproductive, India, Treatment, Tribal women

\section{INTRODUCTION}

Reproductive health of women includes family planning, maternal health, prevention and control of reproductive tract infections (RTIs) and sexually transmitted infections (STIs). It is very important for every adult and adolescent to be aware of their reproductive health because of its implications on the women's health, their children and family, which in turns affect the socioeconomic development of society as a whole. Reproductive health is influenced by gender equity, health education and sexual behaviour. In the developing countries, due to higher levels of gender inequality, female illiteracy, poverty and ignorance, there is high incidence of reproductive tract infections and sexually transmitted infections, which adversely affect reproductive health 
leading to a significant reproductive morbidity and mortality rates. ${ }^{1}$ In addition to these factors, women in underdeveloped nations often deal with unwanted pregnancies and unsafe abortions due to lack of economic independence and atypical sociocultural norms, which worsens their capacity to protect themselves from various RTIs/ STIs. ${ }^{2}$ India is a diverse country, with countless castes, tribes, religions and cultures. There are socioeconomic disparities with in the states, in addition to urban rural divide. In India, about $8 \%$ of the population lives in the rural, geographically distinct tribal communities, which are collectively referred to as 'tribes'. Every tribe has its own customs, traditions and practices. Most of the tribal population in India live in rural areas, with poor health indices of women: high maternal mortality rate and poor reproductive health. ${ }^{3}$ Tribal groups have long existed on the outskirts of Indian society, so, there is a possibility of lack of awareness about the potential health hazards of poor reproductive health.

Through this study, we have tried to explore the factors associated with RTIs /STIs and treatment seeking behaviour among the married tribal women living in rural areas. $^{4}$

\section{METHODS}

It was a community based cross sectional study conducted in the tribal villages, under field practice area of department of community medicine. Taking the prevalence of RTI symptoms among tribal women as $31.1 \%, 5$ with absolute error of $7 \%$, and taking nonresponse rate of $10 \%$, total sample size was calculated to be 190 , rounded off to 200 . Simple random sampling technique was used to select the participants. The study was conducted from May 2019 to November 2019, by paying house to house visits.

A predesigned, pretested and structured questionnaire was used to take the interview of eligible women. The questionnaire was validated by the experts from community medicine and obstetrics and gynaecology department. Questionnaire included questions about sociodemographic profile; menstrual history; obstetric history questions to assess the knowledge regarding RTIs and history of occurrence of any RTI symptom in the past six months and; questions to assess the treatment seeking behaviour for RTI symptoms. The socioeconomic status of women was assessed using BG Prasad scale. ${ }^{6}$ Interview was carried out by the female investigator, with the help of local health worker, by paying the house visits. Investigator introduced herself to the eligible women, explained the purpose of the study, and ensured complete confidentiality of their responses. The objectives of the study were explained to all the women. Informed consent was taken from all the study participants. Complete confidentiality regarding patient information was maintained through all the stages of the study.

\section{Statistical analysis}

Data was analysed using SPSS version 21. Percentage and proportions were calculated for prevalence of the symptoms and treatment seeking behaviour. Univariate analysis using Chi square was performed and a $\mathrm{p}$ value of less than 0.05 was considered significant.

\section{RESULTS}

More than half of study participants were of the age group 26-35 years, followed by 36-45 years and 18-25 years. Majority $(68 \%)$ of the women were housewife by occupation. About $13 \%$ were unskilled workers and $11 \%$ were semiskilled workers. $46 \%$ of study participants were illiterate, $22 \%$ had primary education, followed by $15 \%$ of women who had middle education, $9 \%$ were high school educated and $4 \%$ were graduates. The study participants in this study belonged to social class III $(38 \%)$, social class II (34\%) and social class I (28\%) as shown in (Table 1).

Table 1: Sociodemographic variables of study participants $(n=200)$.

\begin{tabular}{|lll|}
\hline Variables & N & $\%$ \\
\hline Age & & \\
\hline $18-25$ & 34 & 17 \\
\hline $26-35$ & 106 & 53 \\
\hline $36-45$ & 60 & 30 \\
\hline Occupation & & \\
\hline Housewife & 136 & 68 \\
\hline Unskilled worker & 26 & 13 \\
\hline Semiskilled worker & 22 & 11 \\
\hline Skilled worker & 10 & 5 \\
\hline Clerical & 6 & 3 \\
\hline Education & & \\
\hline Illiterate & 92 & 46 \\
\hline Primary & 44 & 22 \\
\hline Middle & 30 & 15 \\
\hline High school & 18 & 9 \\
\hline Secondary & 8 & 4 \\
\hline Graduate & 8 & 4 \\
\hline Socioeconomic status & & \\
\hline Social class V & 56 & 28 \\
\hline Social class IV & 68 & 34 \\
\hline Social class III & 76 & 38 \\
\hline
\end{tabular}

The menstrual and obstetric variables of the study participants are shown in (Table 2). Most (40\%) of the study participants used both sanitary pad and cloth, followed by ordinary cloth $(31 \%)$ and sanitary pad (29\%). Two thirds $(66 \%)$ of the women were using any method of contraception, out of which $42 \%$ were using condoms, $31 \%$ had tubectomy, $13 \%$ used oral contraceptive pills and $12 \%$ had IUCD. Majority (59\%) of the participants had either one or two children, while 
$28 \%$ had three to four children and about $8 \%$ had more than four children. This study revealed that about $35 \%$ had history of abortions, and most of them were induced abortions $(73 \%)$. The most common symptom of RTI, which a woman had heard of, was vaginal discharge $(57 \%)$, followed by itching in genital area (39\%), lower abdominal pain $(29 \%)$, dysuria $(14 \%)$, infertility $(5 \%)$ and dyspareunia $(1 \%)$. Most $(38 \%)$ of them did not know the cause of RTI; however, $29 \%$ revealed poor genital hygiene as one of the causes, $21 \%$ told that the infected sexual partner is the causative factor, while $12 \%$ believed that RTI are transmitted due to the use of public rest rooms.

Table 2: Menstrual and obstetric characteristics of the study participants $(n=200)$.

\begin{tabular}{|c|c|c|}
\hline Variables & $\mathbf{N}$ & $\%$ \\
\hline \multicolumn{3}{|l|}{ Menstrual hygiene practices } \\
\hline Ordinary cloth & 62 & 31 \\
\hline Sanitary pad & 58 & 29 \\
\hline Both sanitary pad and cloth & 80 & 40 \\
\hline \multicolumn{3}{|c|}{ Usage of contraceptive methods } \\
\hline Yes & 132 & 66 \\
\hline No & 68 & 34 \\
\hline \multicolumn{3}{|l|}{ Methods of contraception } \\
\hline Pills & 17 & 13 \\
\hline Condom & 55 & 42 \\
\hline IUCD & 16 & 12 \\
\hline Withdrawal method & 3 & 2 \\
\hline Tubectomy & 41 & 31 \\
\hline \multicolumn{3}{|l|}{ Parity } \\
\hline 0 & 10 & 5 \\
\hline $1-2$ & 118 & 59 \\
\hline $3-4$ & 56 & 28 \\
\hline$>4$ & 16 & 8 \\
\hline \multicolumn{3}{|l|}{ History of abortions } \\
\hline Yes & 70 & 35 \\
\hline No & 130 & 65 \\
\hline \multicolumn{3}{|c|}{ Last abortion, how many years back } \\
\hline$\leq 1$ & 18 & 26 \\
\hline$>1$ & 52 & 84 \\
\hline \multicolumn{3}{|l|}{ Type of abortion } \\
\hline Spontaneous & 19 & 27 \\
\hline Induced & 51 & 73 \\
\hline
\end{tabular}

About $37 \%$ gave the history of experiencing RTI symptoms, vaginal discharge being the most common (46\%) symptom; lower abdominal pain and itching in genital region as the second most common symptom (31\%), followed by dysuria (27\%), dyspareunia (2\%) and infertility (2\%). Regarding the treatment, most (34\%) of the females took treatment from government hospital, followed by $26 \%$ of women who bought the medicines direct from pharmacy (over the counter), about $16 \%$ consulted a private practitioner and 18 women $(24 \%)$ did not take any treatment. Out of the all women who sought treatment, only $57 \%$ were compliant to treatment. Most common reason for non-compliance given by the women was the improvement in symptoms after few days (49\%), second reason was the refusal of partners to being treated (32\%) and $19 \%$ did not take full course of treatment because they could not afford it.

Table 3: Knowledge and prevalence of RTI symptoms among study subjects $(n=200)$.

\begin{tabular}{|c|c|c|}
\hline Variables & $\mathbf{N}$ & $\%$ \\
\hline \multicolumn{3}{|l|}{ Knowledge of symptoms* } \\
\hline Vaginal discharge & 114 & 57 \\
\hline Dyspareunia & 2 & 1 \\
\hline Dysuria & 28 & 14 \\
\hline Lower abdominal pain & 58 & 29 \\
\hline Infertility & 10 & 5 \\
\hline Itching in genital areas & 78 & 39 \\
\hline \multicolumn{3}{|l|}{ How does one get RTI? } \\
\hline Poor genital hygiene & 58 & 29 \\
\hline Infected sexual partner & 42 & 21 \\
\hline Using the public restroom & 24 & 12 \\
\hline Do not know & 76 & 38 \\
\hline \multicolumn{3}{|c|}{ History of symptoms experienced } \\
\hline Yes & 74 & 37 \\
\hline No & 126 & 63 \\
\hline \multicolumn{3}{|c|}{ Types of symptoms experienced* } \\
\hline Vaginal discharge & 34 & 46 \\
\hline Dyspareunia & 1 & 2 \\
\hline Dysuria & 20 & 27 \\
\hline Lower abdominal pain & 23 & 31 \\
\hline Infertility & 1 & 2 \\
\hline Itching in genital areas & 23 & 31 \\
\hline \multicolumn{3}{|c|}{ Treatment seeking symptomatic women } \\
\hline Government hospital & 25 & 34 \\
\hline Private practitioner & 12 & 16 \\
\hline Over the counter & 19 & 26 \\
\hline No treatment & 18 & 24 \\
\hline \multicolumn{3}{|l|}{ Compliance to the treatment } \\
\hline Yes & 32 & 57 \\
\hline No & 24 & 43 \\
\hline \multicolumn{3}{|c|}{ Reason for not completing the course of treatment } \\
\hline Symptoms got better early & 12 & 49 \\
\hline Partner did not take treatment & 8 & 32 \\
\hline Costly medicines & 4 & 19 \\
\hline
\end{tabular}

The association of prevalence of RTI symptoms with various variables is shown in (Table 4). Prevalence of RTI symptoms was higher in younger age group, however the difference was not significant. History of RTI symptoms was found to be significantly associated with education $(\mathrm{p}=0.01)$; prevalence was higher among illiterate and less educated women. Prevalence of symptoms was higher among lower socioeconomic status women and non-users of contraception, with $\mathrm{p}$ value of 0.02 and 0.03 respectively. RTI symptoms were found to 
be higher among women who used ordinary cloth during menstruation and among multiparous women; however the difference was not statistically significant.

\section{DISCUSSION}

In this study, about $37 \%$ had the history of experiencing RTI symptoms. This prevalence is higher than found in the tribal women of Odisha $(31 \%)$ in an assessment study done by Sahoo KC et al. ${ }^{5}$ The possible reason for this discrepancy could be the fact that tribes in India differ from one another in the form of socioeconomic development levels and cultural patterns. Vaginal discharge was the commonest $(46 \%)$ symptom reported by the study participants.

Table 4: Prevalence of RTI symptoms in relation to sociodemographic, obstetric, and behavioural factors.

\begin{tabular}{|c|c|c|c|}
\hline Variables & $\begin{array}{l}\text { History of RTI } \\
\text { symptoms; N (\%) }\end{array}$ & Total & $\begin{array}{l}P \\
\text { value }\end{array}$ \\
\hline \multicolumn{4}{|l|}{ Age (years) } \\
\hline $18-25$ & $14(41)$ & 34 & \multirow{3}{*}{0.57} \\
\hline $26-35$ & $41(39)$ & 106 & \\
\hline $36-45$ & $19(32)$ & 60 & \\
\hline \multicolumn{4}{|l|}{ Education } \\
\hline Illiterate & $45(49)$ & 92 & \multirow{6}{*}{0.01} \\
\hline Primary & $15(34)$ & 44 & \\
\hline Middle & $10(33)$ & 30 & \\
\hline High school & $2(33)$ & 18 & \\
\hline Secondary & $1(11)$ & 8 & \\
\hline Graduate & $1(11)$ & 8 & \\
\hline \multicolumn{4}{|c|}{ Socioeconomic status } \\
\hline Social class V & $29(51)$ & 56 & \multirow{3}{*}{0.02} \\
\hline Social class IV & $21(31)$ & 68 & \\
\hline Social class III & $24(31)$ & 76 & \\
\hline \multicolumn{4}{|c|}{ Menstrual hygiene practices } \\
\hline Ordinary cloth & $28(45)$ & 62 & \multirow{3}{*}{0.27} \\
\hline Sanitary pad & $19(33)$ & 58 & \\
\hline $\begin{array}{l}\text { Both sanitary } \\
\text { pad and cloth }\end{array}$ & $27(34)$ & 80 & \\
\hline \multicolumn{4}{|c|}{ Usage of contraceptive methods } \\
\hline Yes & $42(32)$ & 132 & \multirow{2}{*}{0.03} \\
\hline No & $32(47)$ & 68 & \\
\hline \multicolumn{4}{|l|}{ Parity } \\
\hline 0 & $3(30)$ & 10 & \multirow{4}{*}{0.75} \\
\hline $1-2$ & $41(35)$ & 118 & \\
\hline $3-4$ & $23(41)$ & 56 & \\
\hline$>4$ & $7(44)$ & 16 & \\
\hline
\end{tabular}

Lower abdominal pain and itching in genital region as the second most common symptom (31\%), followed by dysuria (27\%), dyspareunia (2\%) and infertility (2\%). Similar finding was revealed in a study by Mani et al which showed that vaginal discharge was the most common symptom $(23.7 \%)$ among the rural married women in Tamil Nadu. ${ }^{7}$ Other studies done in rural areas of India have revealed vaginal discharge as the common symptom of RTIs /STIs. ${ }^{8}$

A study done in Andhra Pradesh, in 2017, found that the prevalence of reproductive tract infection using the syndromic approach was around $33 \%$, with most of the women reporting vaginal discharge as symptom. ${ }^{9}$ Regarding the knowledge about RTI/STI symptoms, participants had heard of vaginal discharge (57\%), itching in genital area (39\%), lower abdominal pain (29\%), dysuria (14\%), infertility (5\%) and dyspareunia (1\%). Most $(38 \%)$ of them did not know the cause of RTI; however, $29 \%$ revealed poor genital hygiene as one of the causes, $21 \%$ told that the infected sexual partner is the causative factor, while $12 \%$ believed that RTI are transmitted due to the use of public rest rooms. There are various studies done in India, which demonstrated the poor knowledge about reproductive health among women. An assessment study done by Kumari revealed that only $5.4 \%$ of women had adequate knowledge about reproductive health. ${ }^{10}$ Prevalence of RTI was found to be significantly higher in women of lower socioeconomic status, lesser educated females and non-users of contraceptive methods. This finding is similar to the other studies done in India. ${ }^{8,11}$ There is possibility that the women, who were aware about the use of contraceptive methods, also had some insight about the prevention of RTI/STI symptoms.

The prevalence of RTI symptoms were found to be higher among females who used ordinary cloth, however the difference was not significant. Previous studies have found association between poor menstrual hygiene and RTI symptoms. ${ }^{7}$ In a study done in Odisha, involving 558 women, $62 \%$ were diagnosed with at least one reproductive tract infection; $41 \%$ had bacterial vaginosis, and $34 \%$ had candida infection. Authors found that after adjustment for potential confounding factors, the occurrence of these two infections was significantly associated with poor menstrual hygiene management practices. ${ }^{12}$ Lack of significant association in our study could be due to the difference in study tool questionnaire. In our study, only type of absorbent material was asked from participant; however, other practices like washing/ reuse of material, drying/ storage of material and washing of genital area etc. related questions were not asked from participants.

In spite of the availability of appropriate technologies for RTI/STI treatment in India and use of syndromic management in the primary health care setting, most of the RTI/STI infections remain hidden and unrecorded. In our study, about three fourth of the symptomatic women sought treatment. Most (34\%) of the females took treatment from government hospital, followed by $26 \%$ of women who bought the medicines direct from pharmacy (over the counter) and $16 \%$ consulted a private practitioner for the same. Out of all the treatment seeking women, only $57 \%$ were compliant to treatment. Most common reason for non-compliance given by the women 
was the improvement in symptoms after few days (49\%), second reason was the refusal of partners to being treated $(32 \%)$ and about $19 \%$ did not take full course of treatment because they could not afford it. Bit similar findings were revealed in a study done by Prasad et al in 2005 , according to which only one third of symptomatic women had sought any treatment; the possible reasons cited were absence of a female provider in the nearby health centre, distance from home, lack of privacy, costly treatment and a perception that their symptoms were normal. ${ }^{13}$ The reason for a better treatment seeking proportion of women in our study is the fact that syndromic management of RTI/STI s under National AIDS control programme (NACP) phase III was implemented in 2007, which eventually has led to better outcomes. $^{14}$ The study by Prasad was done in 2005, before the implementation of new policy. India is the country with the largest consolidation of tribal population in the world. As per census (2011), the scheduled tribes constitute 84.3 million people, contributing to $8.2 \%$ of the country's population. ${ }^{15}$ There are many governmental schemes and non-governmental programs, focussed on tribal population in India. However, the benefits of these schemes and programs are yet to transform into better health indicators. Studies show that national level health programs require an ideological change in their structure for the benefit of the tribal community, and should include health education for better awareness among tribal women. ${ }^{13,16}$

The findings in our study contribute to the fact that reproductive health status of women is influenced by demography, socioeconomic factors, cultural factors, education and knowledge factors etc. It is very important to focus on these determinants of health, in order to strengthen programmes by the government to improve reproductive health state of marginalised population like tribal women.

\section{CONCLUSION}

In India, majority of women from tribal communities are marginal and unaware of the burden of reproductive morbidities. Many of the reproductive infections are unreported and un treated because of the "culture of silence" or because of inaccessibility to health care. However, in some cases, despite having symptomatic RTIs, women are reluctant to seek medical care, and take over the counter drugs without receiving proper counseling. Hence, knowledge about RTIs is fundamental for the reproductive health of women and is also essential for their ability to meet their reproductive goals.

Funding: No funding sources Conflict of interest: None declared

Ethical approval: The study was approved by the Institutional Ethics Committee

\section{REFERENCES}

1. Sexually transmitted and other reproductive tract infections: a guide to essential practice. Available at: https://www.who.int/reproductivehealth/publications/r tis/9241592656/en/. Accessed on 20 May 2021.

2. Jejeebhoy SJ. Addressing women's reproductive health needs: Priorities for the family welfare programme. Econom Politic Week. 1997:475-84.

3. Kumar R, Singh MM, Kaur A, Kaur M. Reproductive health behaviour of rural women. Journal of the Indian Medical Association. 1995;93(4):129-31.

4. Salehin M. Reproductive health of tribal populations in india: a sustainability approach. Social Develop. 2017;39(2):75-99.

5. Sahoo KC, Dutta A, Nanda P. Assessment Report. Health status of particularly vulnerable tribal groups of odisha. scheduled castes \& scheduled tribes research and training institute. Available at: ttps://repository.tribal.gov.in/bitstream/123456789/74 419/1/SCST_2015_research_0349.pdf. Accessed on 20 May 2021.

6. Pandey VK, Aggarwal P, Kakkar R. Modified BG Prasad Socio-economic Classification, Update-2019. Indian J Commu Health. 2019;31(1):45-9.

7. Mani G. Prevalence of reproductive tract infections among rural married women in Tamil Nadu, India: A community based study. Prevalence. 2014;4(1):45-9.

8. Verma A, Kumar Meena J, Banerjee B. A comparative study of prevalence of RTI/STI symptoms and treatment seeking behaviour among the married women in urban and rural areas of Delhi. Int J Reprod Med. 2015;2015:521-9.

9. Vasireddy S. A study on the prevalence of sexually transmitted infections among women of reproductive age, in urban slums of Guntur city. MRIMS J Health Sci. 2017;5(1):30-4.

10. Kumari MJ. Assessment of knowledge on reproductive health among the women. Int J Current Res Rev. 2016;8(3):19.

11. Ekbal B, Narayana D, Thankappan KR, Ajithkumar K, Mohandas K, Aravindan KP, Kutty VR. Advocacy document-Social determinants of health in Kerala state. Health Sci. 2012;1(2):1-3.

12. Torondel B, Sinha S, Mohanty JR, Swain T, Sahoo P, Panda B, et al. Association between unhygienic menstrual management practices and prevalence of lower reproductive tract infections: a hospital-based cross-sectional study in Odisha, India. BMC Infect dis. 2018;18(1):1-2.

13. Prasad JH, Abraham S, Kurz KM, George V, Lalitha MK, John R, Jayapaul MN, Shetty N, Joseph A. Reproductive tract infections among young married women in Tamil Nadu, India. Int Family Plan Perspect. 2005:73-82.

14. National AIDS Control Programme. Available from:http://www.naco.gov.in/sites/default/files/Nation al_Guidelines_on_PMC_of_RTI_Including_STI\%201 .pdf. Accesssed on 22 July 2021. 
15. Census 2011. Available at: https://www.censusindia. gov.in/Census_and_You/scheduled_castes_and_scedu led_tribes.aspx. Accessed on 26 July, 2021.

16. Kakwani J, Meena JK, Verma A, Dahiya N. Emerging issues and barriers in access to menstrual hygiene management in a tribal district of India. Int $\mathbf{J}$ Commu Med Public Health. 2021;8(4):1985-90.
Cite this article as: Verma A, Patyal A, Mathur M, Mathur N, Hirani J. Prevalence of self-reported reproductive tract infections/sexually transmitted infections symptoms and treatment seeking behavior among the married tribal women in Udaipur, Rajasthan. Int J Reprod Contracept Obstet Gynecol 2021;10:3840-5. 